\title{
Are Christian/Religious People Poor Tippers?
}

\author{
Michael Lynn \\ Cornell University \\ and \\ Benjamin Katz \\ HCD Research
}

Journal of Applied Social Psychology (forthcoming)

The data used in this study was generated and is owned by HCD Research, Inc. of Flemington, N.J., which granted us limited rights to its use in academic research. The authors would like to thank HCD Research for sharing the data with us. Address all correspondence regarding this paper to: Michael Lynn, School of Hotel Administration, Cornell University, Ithaca, NY 14853-6902, (607) 255-8271, wml3@cornell.edu. 


\begin{abstract}
A web based survey was used to assess the relationships of religious faith and frequency of church attendance with tipping under conditions of good and bad service. Results indicated that Jews and those with no religion tipped more than Christians and members of other religions, but that the vast majority of Christians tipped at or above the normative 15 percent of bill size. Worship frequency also significantly interacted with service quality such that the tips of those who frequently worship vary with service quality less than the tips of those who worship less frequently. The practical implications of these results for service workers and restaurants or other service businesses with a large religious clientele are discussed.
\end{abstract}




\section{Are Christian/Religious People Poor Tippers?}

"On these Sundays ... I am commonly stiffed by churchgoers who leave me business cards for their church, cards with bible verses printed on them, and of course the infamous tokens and fake bills which say 'the best tip I can give you is eternal life through Jesus Christ.", (from http://friendlyatheist.com/2009/01/30/dont-serve-the-christians-on-asunday/, accessed 9/3/2010)

"When I delivered pizza in college, I had a rotten feeling every time I went to a door that had a fish outside or one of those 'as for me and my house...' plaques outside the front door"... "I just know that when I went to a person's house that had a plaque like the one I mentioned or 'Jesus Junk' everywhere, I knew I wasn't getting a tip." (from http://thinglings.org/?p=3146 and ... p=3276, accessed 9/3/2010)

"We were halfway between a church and a synagogue, and it turns out both Christians and Jews who have just left a religious ceremony are bad tippers." (from http://pandagon.net/index.php/site/comments/q_of_the_day_bad_tippers_p art_2/, accessed 9/3/2010).

Religion is widely thought to promote pro-social behavior and many religions, like Christianity, encourage adherents to forgive, love, and help one another (Batson, 1983). Thus, it is surprising to learn that many service workers believe highly religious Christians are among the worst tippers in the United States. However, if you Google "bad tippers” or "Christian tipping,” you will find numerous posts by servers expressing that belief. Most often, these negative posts refer to the after church crowd, but server complaints about bad Christian tippers are not limited to the Sunday church crowd as the preceding quotations attest. These quotations, together with the many other similar comments that can be found on the internet, raise a question about whether or not Christian/religious people really are poor tippers. 
Many people will find this topic unpleasant to consider because it seems to demean Christians and other religious people. However, the issue is already being raised by others and ignoring it is not going to make it go away. Religious people in particular should welcome research on this issue, because the outcomes of that research can be used either to dispel false stereotypes or to identify needed reforms in tipping behavior. Furthermore, information about Christian/religious people’s tipping has important practical implications for service workers and for restaurants and other service firms heavily patronized by religious people.

The perception that Christian/religious people tip poorly poses potential problems for the restaurant industry because both qualitative and quantitative research suggest that servers vary their service efforts to different parties with the tip amounts those parties are expected to leave (Barkan and Israeli, 2004; Dirks and Rice, 2004; Rusche and Brewster, 2008). Thus, servers who perceive Christian/religious people as poor tippers may deliver inferior service to the members of these groups seated in their sections. Furthermore, servers who perceive Christian/religious people as poor tippers can be expected to call in sick or otherwise avoid working Sunday afternoons and other shifts when a large religious crowd is expected.

How managers should address these problems depends on whether or not Christian/religious people really do tip poorly and on how strongly their tips vary with service quality. If these groups tip well, then managers should be able to correct any server misperceptions thru education and/or hiring less prejudiced servers. On the other hand, if Christian/religious people really are poor tippers, then these problems are unlikely to be corrected by counter factual denials of the poor tipping. In that case, 
managers could try to focus servers' attention on the effects of service quality. As long as the tips of Christian/religious people vary with service quality, then rational servers should give these groups good service in order to maximize tip income even if the group's tips are lower than desired. Thus, another important question is how strongly the tips of Christian/religious people vary with service quality. If the relationship is weak, then focusing servers' attention on "return to service quality” may not be sufficient to ensure good service to Christian/religious people that leave small tips. Should that prove true, managers will need to try to increase their Christian/religious customers' tip sizes or use incentives other than tipping to motivate their service staff.

In summary, many servers perceive Christian/religious people as poor tippers. As unpleasant as it may be, it is important to ask and answer the question about whether or not this perception is correct as well as the related question about strongly the tips of Christian/religious people are affected by service quality. After a brief review of relevant literature, we address these questions in the study reported below.

\section{Literature Review}

While it is hard to see why Christians per-say would be particularly poor tippers, it is possible that those whose religiousness is reflected in things servers can see or infer (i.e., public displays of faith and religious service attendance on Sundays) tend to tip less on average than others. ${ }^{1}$ Such highly religious people may tip less generously than others for any number of potential reasons -- (1) they may donate money to charity or do other

\footnotetext{
${ }^{1}$ Religiousness is a complex, multi-dimensional construct, with scholars distinguishing between instrinsic and extrinsic religiousness (Allport \& Ross, 1967) and between religious fundamentalism and quest (Hunsberger, 1995). While theoretically interesting, these aspects of religiousness are not the focus of this paper. Rather, we are interested in the aspects of religiousness that are visible or inferable to servers. Attendance at worship services is one such aspect of religiousness because servers can and do infer that many of the well dressed Sunday afternoon crowd are coming from religious services. Furthermore, frequency of religious service attendance has been studied by numerous others and is positively related to the rated importance of religion in peoples' lives (LaBarbera and Gurhan, 1997).
} 
good deeds that they feel gives them a license to tip less (Sachdeva, Iliev and Medin, 2009), (2) they may perceive service workers (especially those who work on religious days) as outsiders who are undeserving of generosity (Saroglou, Pichon, Trompette, Verschueren, and Dernelle, 2005), (3) they may be less informed about or concerned with secular issues like tipping (LaBarbera and Gurhan, 1997), and/or (4) they may have more authoritarian and punitive personalities (Hunsberger, 1995; Kutateladze and Crossman, 2009) that lead them to assess service more harshly and to tip less as a result. Thus, the poor tipping attributed to Christians may actually be due to religiousness in general (or the personality correlates of religiousness) rather than to the specific faith of the poor tippers. In that case, Christians may tip no worse than the members of other faiths and server beliefs to the contrary may be due to the greater numbers and visibility of highly religious Christians than of highly religious Jews, Muslims, Hindu's, and others in the United States.

Of course, it is also possible that servers' perceptions about good vs. bad tippers are simply incorrect. Really poor tips are relatively uncommon as are public displays of Christian faith and the co-occurrence of such relatively rare events has been shown to create illusory correlations in people's minds (Smith, 1991). Furthermore, the apparent hypocrisy of Christians who tip poorly may make them stand out and this enhanced salience may enhance the illusory correlation between Christianity and poor tipping (Smith, 1991).

Despite the widespread and publically expressed belief of many servers that Christians are poor tippers and the practical value of knowing how valid those beliefs are, very little research has examined the effects of religiousness and religious faith on tipping 
behavior. The only study on this issue which we could find is a study reporting that patrons from five restaurants in Virginia who claimed to attend religious services regularly tipped no differently than those who claimed not to attend religious services regularly (Parrett, 2006). This small study from a geographically limited area using an insensitive binomial measure of religiousness is insufficient to resolve the issue.

Accordingly, we set out to assess the relationships of tipping under conditions of good and bad service with religious faith and frequency of church attendance in the internet survey reported below. These data were generated and are owned by HCD Research, Inc. of Flemington, N.J., which granted us limited rights to its use in academic research.

\section{Method}

\section{Participants}

Participants consisted of 535 men and 1,103 women. They ranged in age from 18 to 90 years old. The 1638 Americans surveyed came from a sample of invitees randomly selected from a large national panel maintained by HCD Research. Of the 11,124 email invitations sent, 1,638 respondents who were 18 or older completed the survey. However, 38 of these observations were dropped from analysis due to unrealistic responses to the tipping questions (as described below), so the useable sample was 1,600 U.S. adults.

\section{Principle Questions}

The principle questions asked in the survey and the numeric coding of answers were as follows: 
- Religion: Which of the following best describes your religion?” The response options and numeric codings were "none” = 0 , “Christian” = 1 , “Jewish” = 2, and "Muslim,”" "Buddhist,” "Hindu,” or "Other” = 3.

- Worship frequency: "Please indicate how often you go to a place of worship to practice your religion.” The response options and numeric codings were "several times a day", "once a day", or "several times a week" = 4, "several times a month" $=3$, "several times a year" $=2$, "once a year" or "less than once a year" $=1$, and “never" $=0$.

- Good Service Tip: "Please enter the approximate percentage of tip that you leave at a restaurant if the service is good (based on the total bill). Please enter a numeric response without decimals or symbols.”

- Bad Service Tip: "Please enter the approximate percentage of tip that you leave at a restaurant if the service is bad (based on the total bill). Please enter a numeric response without decimals or symbols.”

\section{$\underline{\text { Control Variables }}$}

Respondents were also asked to provide information about their:

- Age: in years,

- Sex: "male" =1, "female" = 2,

- Income: "less than $\$ 20,000 ”=1$, “ $\$ 20,000-\$ 24,999 ”=2$, “ $\$ 25,000-\$ 34,999 ”=$ 3, “\$35,000 - \$49,999” = 4, “\$50,000 - \$74,999” = 5, \$75,000 - \$99,999” = 6, $“ \$ 100,000-\$ 124,999 ”=7, \$ 125,000$ - $\$ 149,999 ”=8$, “\$150,000 or more” = 9, "prefer not to answer" and missing values = 5 (the median response), 
- Race: "White/Caucasian” = 1, all others (i.e., "African American,” "Asian or Pacific Islander,” "Hispanic origin/Latino,” “Native American, Eskimo, Aleut or Native Alaskan,” “Other (please specify)," "Prefer not to answer," and no response/missing value) $=0$,

- Marital status: "married" = 1, all others (i.e., "Single, never married," "Living with partner,” “ “Separated,” "Divorced,” "Widowed,” "Prefer not to answer,” and no response/missing value) $=0$, and

- Region of residence: "Northeast" = 1, all other (i.e., "Midwest," "South," and "West or Pacific") =0. (Note: This coding was selected because the Northeast was the only region with average tips that significantly differed from the others.)

\section{Results and Discussion}

A preliminary examination of the tipping measures revealed a number of extreme values of questionable validity. To minimize the effects of these unrealistic responses, 33 observations for which good and/or bad service tips exceeded 45 percent and 5 observations for which bad service tips exceeded good service tips were dropped from analysis. Descriptive summaries of the variables in the final data set are presented in

\section{Table 1.}

\section{Religion and Tipping}

The effects of religion on tipping were assessed in a repeated measures general linear model with good vs bad service as a within subjects factor, religion as a between subjects factor, and age, sex, income, race, marital status, and region of residence as co- 
variates (see Tables 2 and 3). This analysis produced a significant main effect for religion $(\mathrm{F}(3,1590)=6.11, \mathrm{p}<.001)$ and a non-significant religion by service interaction $(\mathrm{F}(3$, $1590)=1.36$, n.s.). Post hoc comparisons indicated that people with no religion (hereafter called "non-affiliates") and Jews both tipped more than Christians and members of other religions ( $\mathrm{M}_{\text {average tip }}=13.56$ and 14.16 vs 12.85 and 12.29 respectively) and that this pattern of differences was consistent across good and bad service (see Table 4). The current data do not speak to why non-affiliates and Jews would tip more than others, but one possibility is that the greater secularity of non-affiliates and the greater education levels of Jews (Pew Research Center, 2008) make them more familiar with the 15 to 20 percent restaurant tipping norm.

While the lower tips of Christians as compared with non-affiliates and Jews might appear to support servers' claims that Christians are poor tippers, a more careful analysis undermines that conclusion. First, 70 percent of the sample is Christian as compared to 12 percent non-affiliated, 8 percent Jewish, and 10 percent members of other religions. Thus, considering the population of tippers as a whole, it makes more sense to describe non-affiliates and Jews as unusually good tippers than to describe Christians as unusually bad tippers. Second, Christians leave an average tip of 17.3 percent when the service is good and this is well within the 15 to 20 percent restaurant tipping norm, so on average Christians are not bad tippers. Third, if you define poor tippers as those leaving less than a 15 percent tip for good service then only 13 percent of Christians are poor tippers. Granted this percentage is higher than the 7 percent of non-affiliates and 2 percent of Jews that would be classified as poor tippers under the same criteria, but it seems 
unreasonable to label an entire group based on the behavior of only 13 percent of its members.

\section{Worship Frequency and Tipping}

The effects of frequency of worship on tipping were assessed in a repeated measures general linear model with good vs bad service as a within subjects factor, the linear contrast of frequency of worship as a between subjects factor, and age, sex, income, race, marital status, region of residence and faith as co-variates (see Tables 5 and 6). This analysis produced a non-significant effect of worship frequency $(\mathrm{F}(1,1589)=$ 0.14 , n.s.). Thus, more religious people (as reflected in worship frequency) are not particularly poor tippers and servers' perceptions that very religious Christians tip poorly are incorrect. ${ }^{2}$

The analyses of worship frequency did produce a significant worship frequency by service interaction $(\mathrm{F}(1,1589)=9.58, \mathrm{p}<.003)$. Separate analyses for bad and good service indicated that tips increased marginally significantly with worship frequency when service is bad $(\mathrm{B}=.20, \mathrm{t}(1589)=1.79, \mathrm{p}<.08)$ and decreased non-significantly with worship frequency when service is good $(\mathrm{B}=-.13$, $\mathrm{t}(1589)=-1.38$, n.s.). In other words, the effects of service quality on tips were stronger the less frequently the tipper attended religious services (see Table 7). However, this interaction effect was so small compared to the main effect of service quality, that it has no real practical implications for servers or service delivery. More important are the potential theoretical implications of this interaction, which is at odds with a tendency for religious people to have stronger beliefs in a just world (Furnham, 2003). Among other possibilities, the interaction could

\footnotetext{
${ }^{2}$ A separate analysis using only data from Christians produced results very similar to those reported for all respondents.
} 
be due to an effect of worship frequency on commitment to the religious value of forgiveness (see Gorsuch and Hao, 1993). Unfortunately, testing this possibility is beyond the current data so it is left as a theoretically interesting avenue for future research.

\section{Other Effects on Tipping}

Our analyses also found that older people, Whites, unmarried people, higher income people, and residents of the Northeast all tip more than their counterparts (see Tables 6 and 7). The effects of age, race and income replicate previous findings (see Lynn and Thomas-Haysbert, 2003; Lynn 2009) and the finding about region of residence compliments a previous research finding that residents of the Northeast have the greatest familiarity with the restaurant tipping norm (see Lynn, 2006). Interestingly, the age and region of residence effects are significantly stronger when service is bad than when it is good (see Tables 5 and 7), meaning that the elderly and residents of the Northeast vary their tips with service quality more than do younger people and those living elsewhere in the United States.

\section{Conclusions}

The results of this study produced three notable findings about the relationships between religion and tipping. First, Jews and those with no religion tip significantly more than Christians and members of other religions. However, the average Christian tips 17 percent of the bill when receiving good restaurant service and only 13 out of 100 Christians receiving good service leave a tip below 15 percent of the bill. Second, worship frequency has no significant main effect on reported tipping. Third, worship 
frequency significantly interacts with service quality such that the effects of service quality on tips were stronger the less frequently the tipper attends religious services.

From a theoretical perspective, it would be good to know why the observed relationships between religion and tipping occur. We have speculated that the greater secularity of non-affiliates and the greater education levels of Jews (Pew Research Center, 2008) make them more familiar with the 15 to 20 percent restaurant tipping norm and that this may explain why they tip more than others. We have also speculated that commitment to the religious value of forgiveness (Gorsuch and Hao, 1993) may explain why the effects of service quality on tips were weaker the more frequently the tipper attends religious services. However, numerous other explanations are also possible and the current data do not permit tests of any explanatory ideas, so those tests are left to future research.

From a practical perspective, the results of this study indicate that Christians and church goers are not particularly bad tippers. Thus, there is no widespread financial incentive for servers to avoid working Sunday shifts or to discriminate in service delivery to Christian/religious customers and no widespread need for restaurants or other service firms with a large Christian/religious clientele to abandon tipping as an incentive system. However, to end discussion of the matter with these conclusions would be too simplistic. Sometimes, servers' perceptions that Christians tip badly are undoubtedly biased and without strong foundation. Really poor tippers are relatively uncommon as are public displays of Christian faith and the co-occurrence of such relatively rare events has been shown to create illusory correlations in people's minds (Smith, 1991). Furthermore, the apparent hypocrisy of Christians who tip poorly may make them stand out and this enhanced salience may enhance the illusory correlation between Christianity and poor 
tipping (Smith, 1991). In such cases, restaurant and other service managers can and should use the current study results to correct any illusory correlations in their tipped employees’ minds.

Other times, servers’ perceptions that Christians tip badly may be incorrect, but nevertheless grounded in local realities that require management action. In some cases, for example, tips may be lower on Sundays than on other days not because Sunday customers are disproportionately Christian (as servers may believe) but because they are more likely to be from lower socio-economic classes or to be infrequent restaurant patrons unfamiliar with tipping norms. In such cases, restaurant and other service mangers should still share the current study results with their tipped employees to disabuse them of their erroneous beliefs about Christians being poor tippers, but cannot rely on tipping combined with such educational efforts to motivate the employees to deliver good service to the poor tippers. To motivate employees and ensure good service for all customers, service firms may need to take additional steps like: (i) printing tipping guidelines/suggestions on menus and checks in an attempt to increase their customers' tip sizes, (ii) replacing voluntary tipping with automatic service charges (especially for Sunday brunches or for large groups), and/or (iii) tying job security to the ratings of mystery shoppers who are hired to evaluate employee service efforts.

The current study has two limitations that deserve discussion. First, the survey asked people how much they generally tip rather than observing actual tipping behavior. What people say they do is not necessarily an accurate indication of what they actually do because people may not know how they behave or why and may not report honestly even if they do know. In the current case of an anonymous internet survey, impression 
management demands should have been minimal, but lack of self-awareness is a real threat. For example, the current results replicate other general surveys in finding that people say their tips are strongly related to service quality, but previous research has shown that the relationship is actually weak (Lynn and McCall, 2000). Thus, I do not trust the current study’s estimates of how strongly service quality effects tipping. However, people are generally aware of their deliberate behaviors and the conscious considerations underlying them. Since tipping is largely a conscious and deliberate act as evidenced by general compliance with the 15 to 20 percent tipping norm (people cannot calculate a tip percentage unconsciously), the things people self-report about their tipping habits are meaningful. In fact, surveys like ours have replicated race differences in tipping found using other methodologies and have produced other theoretically meaningful results (see Lynn, 2009), so they should not be completely discounted.

Second, the survey asked people how much they tipped when the service was good and when it was bad, but did not ask them to actually evaluate a particular service experience. Thus, it is possible that Christians and/or other highly religious people are harsher judges of service quality than are others. If so, then Christian/religious people may tip substantially less than others given the same objective service despite our findings that they do not do so given the same subjective levels of service. This possibility deserves investigation in future research.

In summary, the current study found that faith and worship frequency effects on tipping are quite small and do not justify discrimination against religious people in service delivery. Restaurant managers and others can use these results to refute many servers' claims that religious Christians are poor tippers. Although small, the 
relationships of faith and worship frequency with self-reported tipping behavior that were observed are potentially interesting from a theoretical perspective and future research should develop and test explanations for those relationships. 


\section{References}

Allport, G.W. and Ross, J.M. (1967). Personal religious orientationa nd prejudice. Journal of Personality and Social Psychology, 5, 432-443.

Barkan, R. \& A. Israeli, (2004). Servers' roles as experts and managers of tipping. The Service Industries Journal, 24(6), 91-108.

Batson, C.D., (1983). Sociobiology and the role of religion in promoting prosocial behavior: An alternative view. Journal of Personality and Social Psychology, 45, $1380-1385$.

Dirk, D. \& Rice, S. (2004). “Dining while Black:” Tipping as social artifact. Cornell

Hotel and Restaurant Administration Quarterly, 45, 30-47.

Farwell, L. and Weiner, B., (2000). Bleeding hearts and the heartless: Popular perceptions of liberal and conservative ideologies. Personality and Social Psychology Bulletin, 26, 845-852.

Furnham, A. (2003). Belief in a just world: Research progress over the past decade. Personality and Individual Differences, 34, 795-817.

Gorsuch, R.L. and Hao, J.Y., (1993). Forgiveness: An exploratory factor analysis and its relationships to religious variables. Review of Religious Research, 34, 333-347.

Hunsberger, B., (1995). Religion and prejudice: the role of religious fundamentalism, quest, and right-wing authoritarianism. Journal of Social Issues, 51, 113-129.

Kutateladze, B. and Crossman, A.M., (2009). An exploratory analysis of gender differences in punitiveness in two countries. International Criminal Justice Review, $19,322-343$

LaBarbera, P.A. and Gurhan, Z. (1997). The role of materialism, religiosity and demographics in subjective well-being. Psychology and Marketing, 14 (1), 71-97.

Lynn, M., (2006). Geo-demographic differences in knowledge about the restaurant tipping norm. Journal of Applied Social Psychology, 36, 740-750.

Lynn, M., (2009). Individual differences in self-attributed motives for tipping: Antecedents, consequences and implications. International Journal of Hospitality Management, 28, 432-438. 
Lynn, M. and McCall, M. (2000). Gratitude and gratuity: A meta-analysis of research on the service-tipping relationship. Journal of Socio-Economics, 29, 203-214.

Lynn, M. and Thomas-Haysbert, C., (2003). Ethnic differencesin tipping: Evidence, explanations and implications. Journal of Applied Social Psychology, 33, 1747-1772.

May, J.L., (1985). Authoritarianism and applicant's sex and attitudes as determinants of perceived need and deservingness in a charity situation. The High School Journal, 68, 190-196.

Parrett, M.B. (2006). An analysis of the determinants of tipping behavior: A laboratory experiment and evidence from restaurant tipping. Southern Economic Journal, 73 (2), 489-514.

Pew Research Center, (2008). U.S. Religious Landscape Survey. The Pew Forum on Religion and Public Life, available online at http://religions.pewforum.org/pdf/reportreligious-landscape-study-full.pdf, accessed 9-12, 2010.

Rusche, S.E. \& Brewster, Z.W. (2008). “Because they tip for shit!”: The social

psychology of everyday racism in restaurants. Sociology Compass, 2/6, 2008-2029.

Sachdeva, S., Iliev, R. and Medin, D.L. (2009). Sinning saints and saintly sinners: The paraox of moral self-regulation. Psychological Science, 20, 523-528.

Saroglou, V., Pichon, I., Trompette, L., Verschueren, M and Dernelle, R. (2005).

Prosocial behavior and religion: New evidence based on projective measures and peer ratings. Journal for the Scientific Study of Religion, 44 (3), 323-348.

Smith, E.R., (1991). Illusory correlation in a simulated exemplar-based memory. Journal of Experimental Social Psychology, 27, 107-123. 
Table 1. Descriptive statistics.

Std.

\begin{tabular}{lrrrrr} 
& $\mathrm{N}$ & Minimum & Maximum & Mean & Deviation \\
\hline Religion & & & & & \\
- None $(\mathrm{Y}=1 / \mathrm{N}=0)$ & 1600 & .00 & 1.00 & .1206 & .32579 \\
- Christian $(\mathrm{Y}=1 / \mathrm{N}=0)$ & 1600 & .00 & 1.00 & .7006 & .45813 \\
- Jewish $(\mathrm{Y}=1 / \mathrm{N}=0)$ & 1600 & .00 & 1.00 & .0794 & .27041 \\
- Other religion $(\mathrm{Y}=1 / \mathrm{N}=0)$ & 1600 & .00 & 1.00 & .0994 & .29926 \\
Worship frequency & 1600 & .00 & 7.00 & 2.4219 & 1.80095 \\
Good service tip $(\%)$ & 1600 & 0 & 45 & 17.41 & 4.620 \\
Bad service tip $(\%)$ & 1600 & 0 & 40 & 8.56 & 5.367 \\
Age & 1600 & 18 & 90 & 43.18 & 14.068 \\
Sex (m=1, $\mathrm{f}=2)$ & 1600 & 1 & 2 & 1.67 & .469 \\
Income & 1600 & 1.00 & 9.00 & 4.9488 & 1.89132 \\
Race (white=1, other =0) & 1600 & .00 & 1.00 & .6831 & .46540 \\
Marital Status (married =1, other=0) & 1600 & .00 & 1.00 & .5331 & .49906 \\
Region (Northeast=1, other =0) & 1600 & .00 & 1.00 & .2556 & .43635 \\
\hline
\end{tabular}


Table 2. Tests of within-subjects effects (Dependent measure: Tip Percentage)

\begin{tabular}{lrrrrr}
\hline Source & \multicolumn{1}{c}{$\begin{array}{c}\text { Type III Sum of } \\
\text { Squares }\end{array}$} & df & Mean Square & \multicolumn{1}{c}{ F } & \multicolumn{1}{c}{ Sig. } \\
\hline Service & 1470.667 & 1 & 1470.667 & 116.907 & .000 \\
Service * Age & 169.664 & 1 & 169.664 & 13.487 & .000 \\
Service* Sex & 32.491 & 1 & 32.491 & 2.583 & .108 \\
Service* Income & 2.543 & 1 & 2.543 & .202 & .653 \\
Service * Race & 5.889 & 1 & 5.889 & .468 & .494 \\
Service * Marital status & .001 & 1 & .001 & .000 & .992 \\
Service * Region & 69.701 & 1 & 69.701 & 5.541 & .019 \\
Service * Religion & 51.151 & 3 & 17.050 & 1.355 & .255 \\
Error(factor1) & 20001.863 & 1590 & 12.580 & & \\
\hline
\end{tabular}

Table 3. Tests of between subjects effects (Dependent measure: Tip Percentage)

\begin{tabular}{|c|c|c|c|c|c|}
\hline Source & $\begin{array}{c}\text { Type III Sum of } \\
\text { Squares }\end{array}$ & df & Mean Square & $\mathrm{F}$ & Sig. \\
\hline Intercept & 10416.642 & 1 & 10416.642 & 300.709 & .000 \\
\hline Age & 256.757 & 1 & 256.757 & 7.412 & .007 \\
\hline Sex & 45.849 & 1 & 45.849 & 1.324 & .250 \\
\hline Income & 1999.367 & 1 & 1999.367 & 57.718 & .000 \\
\hline Race & 538.109 & 1 & 538.109 & 15.534 & .000 \\
\hline Marital status & 180.388 & 1 & 180.388 & 5.207 & .023 \\
\hline Region & 398.957 & 1 & 398.957 & 11.517 & .001 \\
\hline Religion & 635.408 & 3 & 211.803 & 6.114 & .000 \\
\hline Error & 55078.016 & 1590 & 34.640 & & \\
\hline
\end{tabular}


Table 4. Estimated marginal means (and standard errors) by religion.

\begin{tabular}{lllll}
\hline Religion & $\mathrm{N}$ & Average Tip (\%) & Good Service Tip (\%) & Bad Service Tip (\%) \\
\hline None & 193 & $13.56^{\mathrm{a}}$ & $18.18^{\mathrm{a}}$ & $8.94^{\mathrm{ab}}$ \\
& & $(.30)$ & $(.33)$ & $(.38)$ \\
Christian & \multirow{2}{*}{1121} & $12.85^{\mathrm{b}}$ & $17.30^{\mathrm{b}}$ & $8.40^{\mathrm{a}}$ \\
& & $(.13)$ & $(.14)$ & $(.16)$ \\
Jewish & \multirow{2}{*}{127} & $14.16^{\mathrm{a}}$ & $18.26^{\mathrm{a}}$ & $10.07^{\mathrm{b}}$ \\
& & $(.38)$ & $(.41)$ & $(.48)$ \\
Other & \multirow{2}{*}{159} & $12.29^{\mathrm{b}}$ & $16.55^{\mathrm{b}}$ & $8.02^{\mathrm{a}}$ \\
& & $(.34)$ & $(.36)$ & $(.42)$ \\
\hline
\end{tabular}

Means within columns with different superscripts are significantly different at the .05 level. 
Table 5. Tests of within-subjects effects (Dependent measure: Tip Percentage)

\begin{tabular}{lrrrrr}
\hline Source & $\begin{array}{c}\text { Type III Sum of } \\
\text { Squares }\end{array}$ & df & Mean Square & \multicolumn{1}{c}{ F } & \multicolumn{1}{c}{ Sig. } \\
\hline Service & 1655.674 & 1 & 1655.674 & 132.324 & .000 \\
Service * Age & 158.466 & 1 & 158.466 & 12.665 & .000 \\
Service * Sex & 32.578 & 1 & 32.578 & 2.604 & .107 \\
Service * Income & 2.838 & 1 & 2.838 & .227 & .634 \\
Service * Race & 12.200 & 1 & 12.200 & .975 & .324 \\
Service * Marital status & 1.435 & 1 & 1.435 & .115 & .735 \\
Service * Region & 76.568 & 1 & 76.568 & 6.119 & .013 \\
Service * Non-Afilliate & 5.783 & 1 & 5.783 & .462 & .497 \\
Service * Jewish & 43.417 & 1 & 43.417 & 3.470 & .063 \\
Service * Other Religion & 19.184 & 1 & 19.184 & 1.533 & .216 \\
Service * Worship Frequency & 119.801 & 1 & 119.801 & 9.575 & .002 \\
Error(factor1) & 19882.062 & 1589 & 12.512 & & \\
\hline
\end{tabular}

Table 6. Tests of between subjects effects (Dependent measure: Tip Percentage)

\begin{tabular}{lrrrrr}
\hline Source & $\begin{array}{c}\text { Type III Sum of } \\
\text { Squares }\end{array}$ & df & Mean Square & \multicolumn{1}{c}{ F } & \multicolumn{1}{c}{ Sig. } \\
\hline Intercept & 8649.545 & 1 & 8649.545 & 249.561 & .000 \\
Age & 253.645 & 1 & 253.645 & 7.318 & .007 \\
Sex & 45.869 & 1 & 45.869 & 1.323 & .250 \\
Income & 1997.630 & 1 & 1997.630 & 57.637 & .000 \\
Race & 542.862 & 1 & 542.862 & 15.663 & .000 \\
Marital Status & 184.602 & 1 & 184.602 & 5.326 & .021 \\
Region & 401.654 & 1 & 401.654 & 11.589 & .001 \\
Non-Affiliated & 151.294 & 1 & 151.294 & 4.365 & .037 \\
Jewish & 373.091 & 1 & 373.091 & 10.765 & .001 \\
Other Religion & 79.472 & 1 & 79.472 & 2.293 & .130 \\
Worship & 4.765 & 1 & 4.765 & .137 & .711 \\
Frequency & & & & & \\
Error & 55073.252 & 1589 & 34.659 & & \\
\hline
\end{tabular}


Table 7. Separate tests of effects on tips when service is bad and good.

\begin{tabular}{|c|c|c|c|c|c|}
\hline \multirow[t]{2}{*}{ Dependent Variable } & \multirow[t]{2}{*}{ Parameter } & \multicolumn{3}{|c|}{ Std. } & \multirow[b]{2}{*}{ Sig. } \\
\hline & & $\mathrm{B}$ & Error & $\mathrm{t}$ & \\
\hline \multirow[t]{11}{*}{ Bad service tip (\%) } & Intercept & 5.853 & .822 & 7.117 & .000 \\
\hline & Age & -.037 & .009 & -3.879 & .000 \\
\hline & Sex & .481 & .283 & 1.698 & .090 \\
\hline & Income & .440 & .075 & 5.852 & .000 \\
\hline & Race & 1.080 & .296 & 3.645 & .000 \\
\hline & Marital Status & -.596 & .296 & -2.011 & .044 \\
\hline & Region & 1.197 & .306 & 3.917 & .000 \\
\hline & Non-Affiliated & .924 & .462 & 2.001 & .046 \\
\hline & Jewish & 1.783 & .506 & 3.524 & .000 \\
\hline & Other Religion & -.278 & .451 & -.617 & .537 \\
\hline & Worship Frequency & .201 & .113 & 1.786 & .074 \\
\hline \multirow[t]{11}{*}{ Good service tip (\%) } & Intercept & 14.957 & .710 & 21.055 & .000 \\
\hline & Age & -.004 & .008 & -.526 & .599 \\
\hline & Sex & .041 & .244 & .168 & .867 \\
\hline & Income & .474 & .065 & 7.304 & .000 \\
\hline & Race & .798 & .256 & 3.119 & .002 \\
\hline & Marital Status & -.499 & .256 & -1.951 & .051 \\
\hline & Region & .470 & .264 & 1.778 & .076 \\
\hline & Non-Affiliated & 622 & .399 & 1.558 & .119 \\
\hline & Jewish & .876 & .437 & 2.004 & .045 \\
\hline & Other Religion & -.816 & .390 & -2.094 & .036 \\
\hline & Worship Frequency & -.134 & .097 & -1.380 & .168 \\
\hline
\end{tabular}




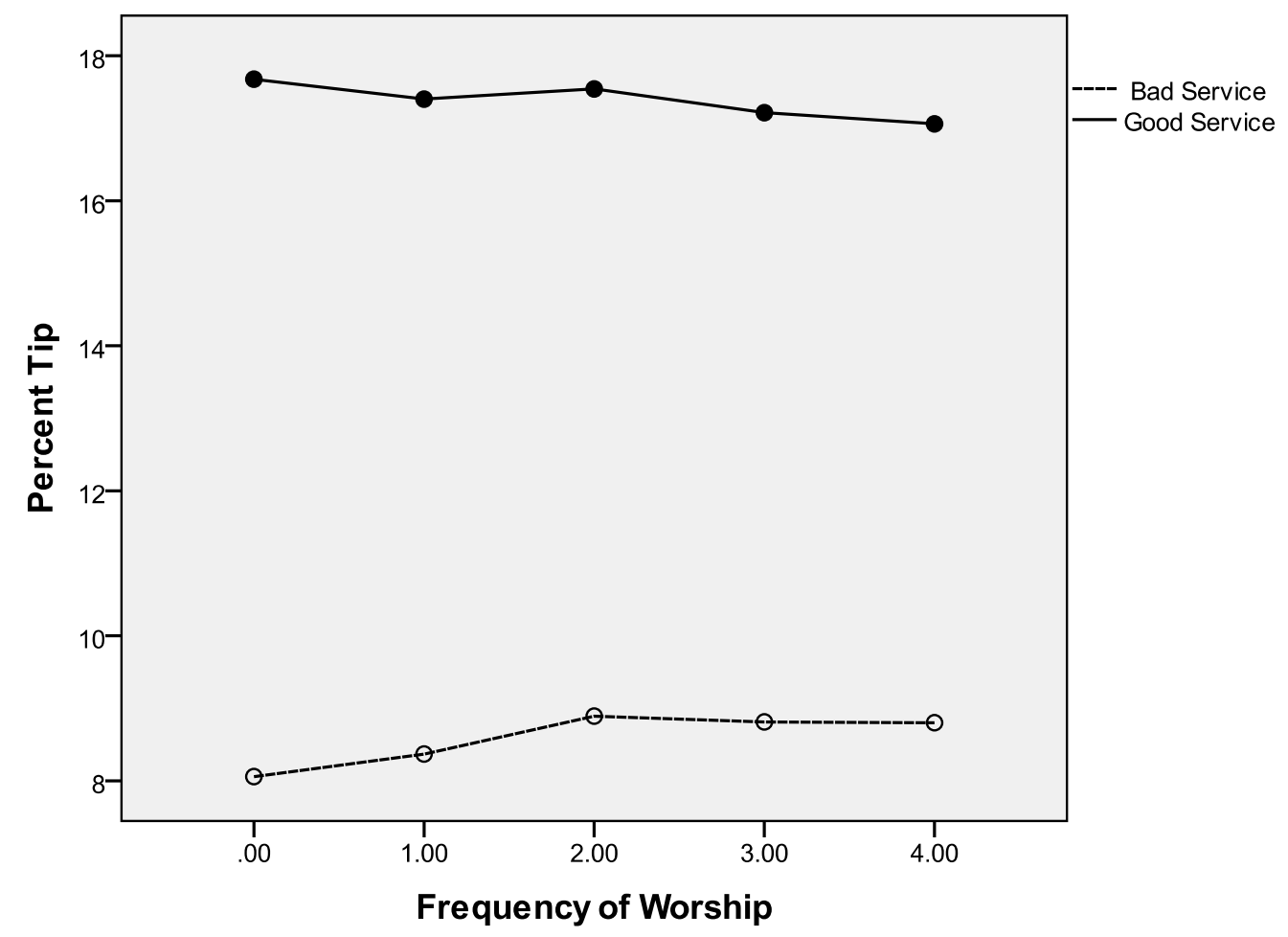

Covariates appearing in the model are evaluated at the following values: Age $=43.18$, Gender $=1.67$, income $=4.9488$, white $=.6831$, married $=.5331$, NRTHEAST $=.2556$, atheist $=.1206$, Jewish $=.0794$, OtherReligion $=.0994$

Figure 1. Effects of worship frequency on tipping when service is good and bad. 